\title{
Increased Plasma Levels of Pentraxin 3 Are Associated with Poor Prognosis of Colorectal Carcinoma Patients
}

\author{
Jie Zhang, ${ }^{1}$ Tai-Yong Wang ${ }^{2}$ and Xue-Cai Niu ${ }^{3}$ \\ ${ }^{1}$ Department of General Surgery, Dezhou People's Hospital, Dezhou, Shandong Province, China \\ ${ }^{2}$ Department of Oncology, Dezhou People's Hospital, Dezhou, Shandong Province, China \\ ${ }^{3}$ Department of Radiology, Jinan Fourth People's Hospital, Jinan, Shandong Province, China
}

\begin{abstract}
Colorectal carcinoma (CRC) is one of the most common cancers globally. It is essential to identify a prognostic predictor for CRC. Pentraxin 3 (PTX3) is a glycoprotein that is secreted by a variety of human cells. It plays an important role in inflammation and immune regulation. Increasing evidence reveals that elevated PTX3 expression is related to poor prognosis in various cancers. The aim of the study was to determine the usefulness of plasma PTX3 level as a prognostic predictor in CRC. Total 184 CRC patients and 216 controls were included. Plasma levels of PTX3 were determined using Enzyme-linked immunosorbent assays. On admission, plasma PTX3 levels in CRC patients were higher than those in controls $(11.8 \pm 2.5 \mathrm{ng} / \mathrm{ml}$ vs. $3.1 \pm 0.9 \mathrm{ng} / \mathrm{ml}, \mathrm{P}<0.001)$. After resection, plasma PTX3 levels in patients were decreased $(6.0 \pm 1.4 \mathrm{ng} / \mathrm{ml}, \mathrm{P}=0.007)$, and were elevated at the time of relapse $(10.8 \pm 2.8 \mathrm{ng} / \mathrm{ml}, \mathrm{P}$ $<0.001$ ). During the 60-month follow-up period, 108 patients suffered from relapse. Plasma PTX3 levels of $\geq 12 \mathrm{ng} / \mathrm{ml}$ on admission were associated with relapse (OR: $3.11,95 \% \mathrm{Cl}: 1.74 \sim 6.29$ ), and tumor-free survival rate in those patients with plasma PTX3 levels of $\geq 12 \mathrm{ng} / \mathrm{ml}$ was lower than that in other patients $(P=0.001)$. Furthermore, plasma PTX3 levels on admission showed positive linear correlations with plasma complement 3,4 and $5 \mathrm{~b} 9$ levels $(P<0.001, P<0.001, P<0.001)$. Therefore, we propose that PTX3 is an independent prognostic indicator in CRC.
\end{abstract}

Keywords: colorectal carcinoma; complement; pentraxin 3; prognosis; relapse

Tohoku J. Exp. Med., 2016 September, 240 (1), 39-46. C 2016 Tohoku University Medical Press

\section{Introduction}

Colorectal carcinoma (CRC) occurs in human colon and rectum. Early symptom includes weak, weight loss, bloody stool and intestinal motility disorder (Compton 2003). Nowadays, CRC has become one of the most common malignancies globally. More than 1.2 million people suffer from and 600,000 patients die of CRC annually (Ferlay et al. 2010; Torre et al. 2015). A variety of screening, diagnostic and treatment methods have been developed for improving prognosis, but CRC is still deadly with elevated morbidities and mortalities, particularly in developing countries (Guo et al. 2012; Brenner et al. 2014). In order to meet the challenge of $\mathrm{CRC}$, some available methods for predicting prognosis and guiding treatment decision are urgently required by clinicians.

Pentraxin 3 (PTX3) is a glycoprotein with a molecular mass of $45 \mathrm{kDa}$. It plays an essential role in immune regulation, inflammation, apoptosis and vascular remodeling (Mantovani et al. 2003; Garlanda et al. 2005). PTX3 can be secreted by various human cell types, including dentritic cells, macrophages, and fibroblasts (Savchenko et al. 2008), and its secretion might be regulated by many factors, such as interleukin- $1 \beta$, tumor necrosis factor $\alpha$, microbial infection and tissue injury (Bottazzi et al. 2006; Cieślik and Hrycek 2012). In recent years, an increasing number of studies have focused on the potential relationship between PTX3 and various malignancies, particularly lung cancer. Zhang et al. (2013) revealed that PTX3 was significantly increased in both cancer tissues and plasma in lung cancer patients, which might improve identification of patients with cancer from those with non-malignant lung diseases. Liu et al. (2014) suggested that high PTX3 expression appeared to correlate with aggressive behavior in small cell lung cancer. Infante et al. (2016) revealed that increased expression of PTX3 might be related to poor prognosis in lung cancer via local inflammation mechanism. Takeda et al. (2015) reported that PTX3 might be helpful for diagnosis of febrile neutropenia in lung cancer patients. Some studies have also focused on liposarcoma, pancreatic cancer, glioma and $\mathrm{CRC}$, and have partly revealed prognostic role of PTX3 in these types of cancers (Germano et al. 2010; Kondo et al. 2013; Locatelli et al. 2013; Di Caro et al. 2016). However, potential mechanism of PTX3 on

Received May 9, 2016; revised and accepted August 17, 2016. Published online August 26, 2016; doi: 10.1620/tjem.240.39.

Correspondence: Tai-Yong Wang, Department of Oncology, Dezhou People's Hospital, No.1751, Xinhu Street, Dezhou, Shandong Province 253014, China.

e-mail: taiyong446688@126.com 
prognostic utility in these cancers has not been well elucidated.

Therefore, we conducted a prospective study to further determine the diagnostic and prognostic significances of PTX3 in CRC patients, and to preliminary explore the mechanism in CRC patients.

\section{Materials and Methods}

The study was approved by the ethics committee of Dezhou People's Hospital. A total of 200 consecutive patients with CRC were included in the study from Dezhou People's Hospital between January 1, 2008 and June 30, 2009. Inclusion criteria were listed as follows: (1) diagnosis was established pathologically; (2) patients had never received radiotherapy, chemotherapy, surgery and other anti-tumor therapies on admission; (3) after blood specimen collection, patients would undergo CRC resection; and (4) patients had not suffered from coronary heart disease, cerebral infarction, diabetes mellitus, autoimmune disease, severe infection and other malignancies. Patients with stage IV CRC were excluded, because they were unable to undergo resection.

A total of 50 colorectal polyp patients and 216 healthy controls were selected from medical examination center, Dezhou People's Hospital. In colorectal polyp patients, colonoscopies were conducted for establishing the diagnosis. Age-matched healthy controls did not suffer from colorectal polyps, ulcerative colitis, cardiovascular disease, diabetes mellitus, autoimmune disease, severe infection or other malignancies. All CRC patients, colorectal polyp patients and healthy controls were explained the whole research process, and all of them signed informed consents.

Blood specimens were collected from participants at the first time when they were included in the study. Four weeks after resection, blood specimen was obtained from each CRC patient again. All CRC patients agreed to be followed-up for 60 months, and tumor relapse was regarded as poor prognosis. If an included CRC patient suffered from relapse in the follow-up period, blood specimen was collected for a third time.

Blood specimens were centrifuged at 3,000 rpm for 10 minutes, and plasma specimens were separated and stored at $-80^{\circ} \mathrm{C}$ for later analyses. All specimens were stored for no more than 3 months. Plasma levels of PTX3, complement 3 (C3), complement 4 (C4) and complement 5 b9 (C5b9) were measured using commercial enzyme linked immunosorbent assay (ELISA) kits (R\&D systems, Minneapolis, MN, USA). All procedures were carried out in accordance with manufacturer's instructions. Demographic and medical information of participants were obtained from medical records and face-to-face interviews at admission.

Statistical Product and Service Solution version 17.0 (SPSS, Chicago, IL, USA) was adopted for statistical analysis in the study. There were two kinds of variables in the study. They were continuous variable (e.g. plasma level of PTX3) and categorical variable (e.g. gender). Continuous variable was represented by mean $\pm \mathrm{SD}$, and categorical variable was represented by frequency. Differences of continuous variables and categorical variables were detected separately by independent sample $t$ test and Chi-square test. Difference of recurrence free survival rate in postoperative patients was evaluated by survival analysis. Pearson correlation analysis was conducted to determine the relationship between plasma level of PTX3 and plasma levels of complement proteins ( $\mathrm{C} 3, \mathrm{C} 4$ and $\mathrm{C} 5 \mathrm{~b} 9)$. A P value of less than 0.05 was considered to be statistical significance. Receiver oper- ating characteristic curve analysis was conducted to determine cut off values for plasma levels of PTX3, C3, C4 and C5b9. Association between several factors (e.g. plasma PTX3 level) and tumor relapse in patients was determined by logistic regression analysis. In such analysis, odds ratio (OR) with $95 \%$ confidence interval (CI) was obtained. If a $95 \%$ CI did not include value " 1 ", this analysis was considered to be statistical significance.

\section{Results}

Among the 200 CRC patients, ten patients were lost and another six patients were died of cardiovascular diseases in the follow-up period. Thus, 184 CRC patients, 50 colorectal polyp patients and 216 healthy controls were analyzed in the present study (Table 1). There was no significant difference in sex, age, body mass index (BMI), smoking history, drinking history or family history of CRC among CRC patients, colorectal polyp patients and healthy controls. Plasma levels of PTX3, C3, C4 or C5b9 were significantly higher in CRC patients than those in healthy controls $(\mathrm{P}<0.001$ for each). In contrast, plasma levels of these four proteins were comparable between colorectal polyp patients and healthy controls $(\mathrm{P}>0.05)$.

Compared with controls $(3.1 \pm 0.9 \mathrm{ng} / \mathrm{ml})$, plasma levels of PTX3 on admission were significantly higher in CRC patients $(11.8 \pm 2.5 \mathrm{ng} / \mathrm{ml}, \mathrm{P}<0.001)$ (Fig. 1). By four weeks after resection, plasma levels of PTX3 in patients were remarkably decreased $(6.0 \pm 1.4 \mathrm{ng} / \mathrm{ml}, \mathrm{P}=$ 0.007). In the follow-up period, tumor relapse occurred in 108 postoperative patients, and plasma levels of PTX3 in these patients were increased to $10.8 \pm 2.8 \mathrm{ng} / \mathrm{ml}$ again $(\mathrm{P}<$ $0.001)$.

The 184 CRC patients were divided into several subgroups according to smoking history, drinking history, onset of colorectal polyps, onset of ulcerative colitis, and family history of CRC (Table 2). The plasma levels of PTX3 were similar among those subgroups: $\mathrm{P}=0.944, \mathrm{P}=0.735, \mathrm{P}=$ $0.843, \mathrm{P}=0.745$, and $\mathrm{P}=0.634$, respectively. Thus, plasma PTX3 levels might not be affected by the above factors.

The receiver operating characteristic curve analysis revealed that a cutoff point for plasma level of PTX3 on admission was $12.0 \mathrm{ng} / \mathrm{ml}$ (Fig. 2), yielding the sensitivity of $81.3 \%$ and the specificity of $69.5 \%$ in predicting tumor relapse in patients (area under the curve $=0.789, \mathrm{P}<$ 0.001). In addition, the cutoff values for plasma levels of $\mathrm{C} 3, \mathrm{C} 4$ and $\mathrm{C} 5 \mathrm{~b} 9$ were $1.6 \mathrm{~g} / \mathrm{L}, 0.5 \mathrm{~g} / \mathrm{L}$, and $841.0 \mathrm{~g} / \mathrm{L}$, respectively (Fig. 2B-D).

The CRC patients were divided into high PTX3 group $(\geq 12 \mathrm{ng} / \mathrm{ml}$ ) and low PTX3 group ( $\geq 12 \mathrm{ng} / \mathrm{ml}$ ) according to the cutoff value $(12.0 \mathrm{ng} / \mathrm{ml})$ on admission. There were 108 tumor relapse patients and 76 tumor-free patients in the follow-up period (Table 3). Tumor relapse was more common in patients with tumor stage II or III and high plasma levels of PTX3 on admission ( $\geq 12 \mathrm{ng} / \mathrm{ml}$ ) compared with that in patients with tumor stage $\mathrm{I}(\mathrm{P}=0.025$ and $\mathrm{P}=0.013)$ and low plasma PTX3 levels $(<12 \mathrm{ng} / \mathrm{ml})(\mathrm{P}<0.001)$. In addition, plasma levels of $\mathrm{C} 3, \mathrm{C} 4$ and $\mathrm{C} 5 \mathrm{~b} 9$ were signifi- 
Table 1. Characteristics of participants in the study.

\begin{tabular}{|c|c|c|c|c|c|c|}
\hline & $\mathrm{CRC}$ & & $\mathrm{CP}$ & Controls & $\mathrm{P}_{\text {value }}^{\mathrm{a}, \mathrm{c}}$ & $\mathrm{P}$ value $\mathrm{b}^{\mathrm{b}, \mathrm{c}}$ \\
\hline Total (n) & 184 & & 50 & 216 & - & \\
\hline \multicolumn{7}{|l|}{$\operatorname{Sex}(n)$} \\
\hline Male & 121 & & 34 & 124 & 0.087 & 0.169 \\
\hline Female & 63 & & 16 & 92 & & \\
\hline Age $(\mathrm{yrs}$, mean $\pm \mathrm{SD})$ & $54.1 \pm 8.8$ & 50.6 & \pm 12.1 & $52.8 \pm 10.2$ & 0.379 & 0.238 \\
\hline $\mathrm{BMI}\left(\mathrm{kg} / \mathrm{m}^{2}\right.$, mean $\left.\pm \mathrm{SD}\right)$ & $20.8 \pm 5.0$ & 23.1 & $1 \pm 6.5$ & $21.5 \pm 5.4$ & 0.698 & 0.210 \\
\hline \multicolumn{7}{|l|}{ Smoking history (n) } \\
\hline Yes & 107 & & 29 & 115 & 0.325 & 0.543 \\
\hline No & 77 & & 21 & 101 & & \\
\hline \multicolumn{7}{|l|}{ Drinking history $(\mathrm{n})$} \\
\hline Yes & 64 & & 20 & 80 & 0.640 & 0.697 \\
\hline No & 120 & & 30 & 136 & & \\
\hline \multicolumn{7}{|l|}{ Family history of CRC (n) } \\
\hline Yes & 46 & & 15 & 42 & 0.181 & 0.101 \\
\hline No & 138 & & 35 & 174 & & \\
\hline Pentraxin $3(\mathrm{ng} / \mathrm{ml})$ & $11.8 \pm 2.5$ & 3.5 & \pm 1.2 & $3.1 \pm 0.9$ & $<0.001$ & 0.537 \\
\hline $\mathrm{C} 3(\mathrm{~g} / \mathrm{L}$, mean $\pm \mathrm{SD})$ & $1.5 \pm 0.4$ & 0.8 & \pm 0.4 & $0.7 \pm 0.3$ & $<0.001$ & 0.325 \\
\hline $\mathrm{C} 4(\mathrm{~g} / \mathrm{L}$, mean $\pm \mathrm{SD})$ & $0.4 \pm 0.1$ & 0.2 & \pm 0.1 & $0.2 \pm 0.1$ & $<0.001$ & 0.769 \\
\hline $\mathrm{C} 5 \mathrm{~b} 9(\mathrm{~g} / \mathrm{L}$, mean $\pm \mathrm{SD})$ & $830.3 \pm 63.5$ & 572.4 & $4 \pm 65.1$ & $550.6 \pm 57.4$ & $<0.001$ & 0.576 \\
\hline
\end{tabular}

${ }^{\mathrm{a} C}$ Colorectal carcinoma group vs. control group.

${ }^{b}$ Colorectal polyps group vs. control group.

'Differences of continuous and categorical variables were detected separately by independent sample $\mathrm{t}$ test and Chi-square test. A P value of less than 0.05 was considered to be statistical significance.

CRC, colorectal carcinoma; CP, colorectal polyps; C3, complement 3; C4, complement 4; C5b9, complement 5b9; SD, standard deviation; BMI, body mass index.

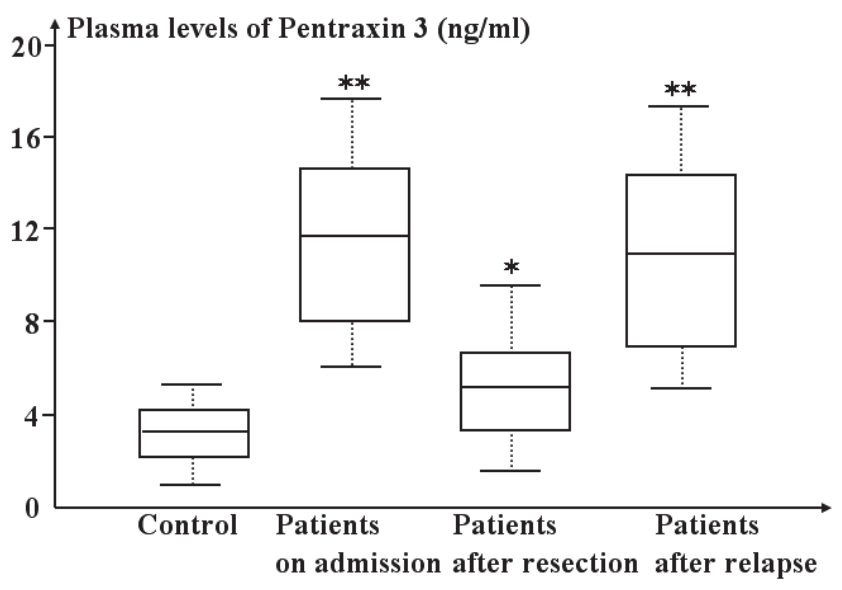

Fig. 1. Plasma levels of pentraxin 3 in colorectal carcinoma patients and healthy controls.

The lower boundary of the boxes indicates the $25^{\text {th }}$ percentile, line within the boxes marks the median, and the higher boundary of the boxes indicates the $75^{\text {th }}$ percentile. Error bars below and above the boxes indicate minimum and maximum values. The data were obtained from 216 control, 184 patients on admission, 184 patients after resection, and 108 patients after relapse $(* \mathrm{P}=0.007$ and $* * \mathrm{P}<0.001$, compared with control).

cantly increased in the relapse patients compared with those in tumor-free patients $(\mathrm{P}=0.001, \mathrm{P}<0.001$, and $\mathrm{P}=0.003$, respectively). However, there was no significant difference in other demographic and pathological factors, such as sex $(P=0.059)$, age $(P=0.078)$, tumor site $(P=0.369)$, tumor size $(\mathrm{P}=0.248)$ and tumor differentiation $(\mathrm{P}=0.917$ and $\mathrm{P}$ $=0.665)$, between tumor relapse patients and tumor free patients (Table 3 ).

In Table 4, logistic multivariate regression analyses revealed that tumor relapse in patients were separately associated with tumor stage II (OR: 2.30, 95\% CI: $1.17 \sim 5.12$ ), tumor stage III (OR: 2.45, 95\% CI: $1.21 \sim 5.78)$ and high level of PTX3 on admission ( $\geq 12 \mathrm{ng} / \mathrm{ml}$ ) (OR: 3.11, 95\% CI: $1.74 \sim 6.29$ ). In Fig. 3, survival analysis also suggested that tumor-free survival rate in patients with low levels of PTX3 on admission $(<12 \mathrm{ng} / \mathrm{ml})$ was significantly higher than that in patients with high level of PTX3 on admission ( $\geq 12 \mathrm{ng} / \mathrm{ml})(\mathrm{P}=0.001)$. Therefore, plasma level of PTX3 on admission might be an independent prognostic factor in CRC patients, and tumor stage might be another important prognostic factor in CRC patients.

Then, we combined the plasma PTX3 level on admission and the tumor stage into one prognostic analysis. In patients with tumor stage II or III, the association between high PTX3 levels ( $\geq 12 \mathrm{ng} / \mathrm{ml}$ ) and tumor relapse in patients was stronger (OR: 9.77, 95\% CI: $4.81 \sim 21.13$ ) (Table 4). However, in patients with tumor stage I, the association between high PTX3 levels ( $\geq 12 \mathrm{ng} / \mathrm{ml}$ ) and tumor relapse was weak (OR: 1.44, 95\% CI: $1.15 \sim 4.75$ ) (Table 4). Therefore, prognostic significance of plasma PTX3 levels was stronger in patients with advanced CRC. The patients with relapse were also divided into high level groups and low level groups according to the cutoff values for plasma levels of C3, C4 and C5b9 (1.6 g/L, $0.5 \mathrm{~g} / \mathrm{L}$ and $841.0 \mathrm{~g} / \mathrm{L})$ 
Table 2. Plasma levels of pentraxin 3 in colorectal carcinoma patients at admission.

\begin{tabular}{|c|c|c|c|}
\hline Subgroups & $\begin{array}{l}\text { No. of patients } \\
\text { (n) }\end{array}$ & $\begin{array}{l}\text { Plasma levels of pentraxin } 3 \\
(\mathrm{ng} / \mathrm{ml}, \text { mean } \pm \mathrm{SD})\end{array}$ & P value \\
\hline \multicolumn{4}{|c|}{ Smoking history } \\
\hline Yes & 107 & $11.9 \pm 2.5$ & 0.944 \\
\hline No & 77 & $11.8 \pm 2.7$ & \\
\hline \multicolumn{4}{|c|}{ Drinking history } \\
\hline Yes & 64 & $11.7 \pm 2.5$ & 0.735 \\
\hline No & 120 & $11.9 \pm 2.6$ & \\
\hline \multicolumn{4}{|l|}{ Onset of CP } \\
\hline Yes & 81 & $11.9 \pm 2.4$ & 0.843 \\
\hline No & 103 & $11.8 \pm 2.7$ & \\
\hline \multicolumn{4}{|l|}{ Onset of UC } \\
\hline Yes & 17 & $12.2 \pm 1.9$ & 0.745 \\
\hline No & 167 & $11.8 \pm 2.6$ & \\
\hline \multicolumn{4}{|c|}{ Family history of CRC } \\
\hline Yes & 46 & $11.6 \pm 2.5$ & 0.634 \\
\hline No & 138 & $11.9 \pm 2.6$ & \\
\hline
\end{tabular}

aDifferences of continuous variables were detected by independent sample $t$ test.

A P value of less than 0.05 was considered to be statistical significance.

CRC, colorectal carcinoma; SD, standard deviation; CP, colorectal polyps; UC, ulcerative colitis.
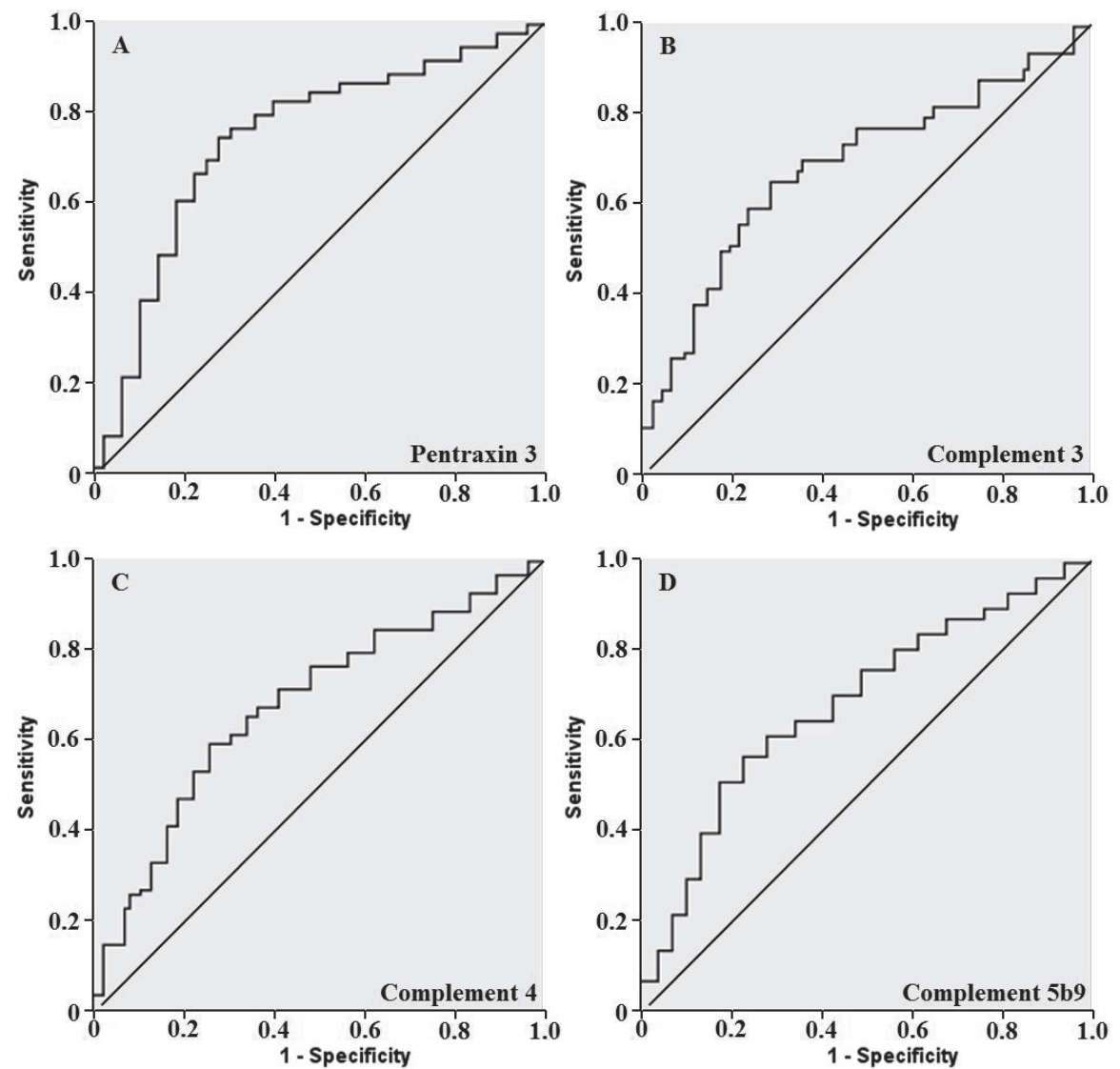

Fig. 2. Receiver operating characteristic curves for tumor free prediction.

A: A cutoff point for plasma level of pentraxin 3 on admission was $12.0 \mathrm{ng} / \mathrm{ml}$, yielding the sensitivity of $81.3 \%$ and the specificity of $69.5 \%$ in predicting prognosis in patients (Area under the curve $=0.789, \mathrm{P}<0.001$ ). B, C and D: Cutoff points for plasma levels of complements 3,4 and $5 \mathrm{~b} 9$ were $1.6 \mathrm{~g} / \mathrm{L}(\mathrm{B}), 0.5 \mathrm{~g} / \mathrm{L}(\mathrm{C})$ and $841.0 \mathrm{~g} / \mathrm{L}$ (D). Sensitivity was $80.1 \%, 82.8 \%$ and $78.8 \%$, and specificity was $65.5 \%, 68.8 \%$ and $63.1 \%$ (Area under the curve $=0.674,0.683$ and 0.669; $\mathrm{P}<0.001, \mathrm{P}<0.001$ and $\mathrm{P}<0.001)$. The data, shown in $\mathrm{A}-\mathrm{D}$, were obtained from 108 patients with tumor relapse and 76 tumor-free patients. 
Table 3. Differences of several factors between relapse patients and tumor free patients in the follow up period.

\begin{tabular}{|c|c|c|c|}
\hline At admission & Tumor free & Relapse & P value \\
\hline Total (n) & 76 & 108 & - \\
\hline \multicolumn{4}{|l|}{ Sex (n) } \\
\hline Male & 44 & 77 & 0.059 \\
\hline Female & 32 & 31 & \\
\hline Age (yrs, mean \pm SD) & $53.4 \pm 7.8$ & $55.2 \pm 9.2$ & 0.078 \\
\hline \multicolumn{4}{|l|}{ Tumor site (n) } \\
\hline Colon & 50 & 64 & 0.369 \\
\hline Rectum & 26 & 44 & \\
\hline \multicolumn{4}{|l|}{ Tumor size (n) } \\
\hline$<5.0 \mathrm{~cm}$ & 28 & 49 & 0.248 \\
\hline$\geqslant 5.0 \mathrm{~cm}$ & 48 & 59 & \\
\hline \multicolumn{4}{|l|}{ Tumor differentiation (n) } \\
\hline Well & 12 & 17 & $0.917^{\mathrm{a}}$ \\
\hline Moderate & 45 & 61 & $0.665^{\mathrm{b}}$ \\
\hline Poor & 19 & 30 & \\
\hline \multicolumn{4}{|l|}{ TNM stage (n) } \\
\hline Stage I & 28 & 18 & $0.025^{\mathrm{c}}$ \\
\hline Stage II & 41 & 59 & $0.013^{\mathrm{d}}$ \\
\hline Stage III & 7 & 31 & \\
\hline Pentraxin 3 (ng/ml) & $8.3 \pm 2.7$ & $14.9 \pm 2.1$ & $<0.001$ \\
\hline $\mathrm{C} 3(\mathrm{~g} / \mathrm{L}$, mean $\pm \mathrm{SD})$ & $1.2 \pm 0.3$ & $1.7 \pm 0.4$ & 0.001 \\
\hline $\mathrm{C} 4(\mathrm{~g} / \mathrm{L}$, mean $\pm \mathrm{SD})$ & $0.4 \pm 0.1$ & $0.5 \pm 0.1$ & $<0.001$ \\
\hline $\mathrm{C} 5 \mathrm{~b} 9(\mathrm{~g} / \mathrm{L}$, mean $\pm \mathrm{SD})$ & $794.4 \pm 60.2$ & $869.4 \pm 65.8$ & 0.003 \\
\hline
\end{tabular}

${ }^{a}$ Well versus moderate.

${ }^{b}$ Moderate versus poor.

${ }^{\mathrm{c} S t a g e ~ I ~ v e r s u s ~ s t a g e ~ I I . ~}$

dStage II versus stage III.

eDifferences of continuous and categorical variables were detected separately by independent sample $t$ test and Chi-square test. A P value of less than 0.05 was considered to be statistical significance.

TNM, tumor node metastasis; SD, standard deviation; C3, complement 3; C4, complement 4; C5b9, complement 5 b9.
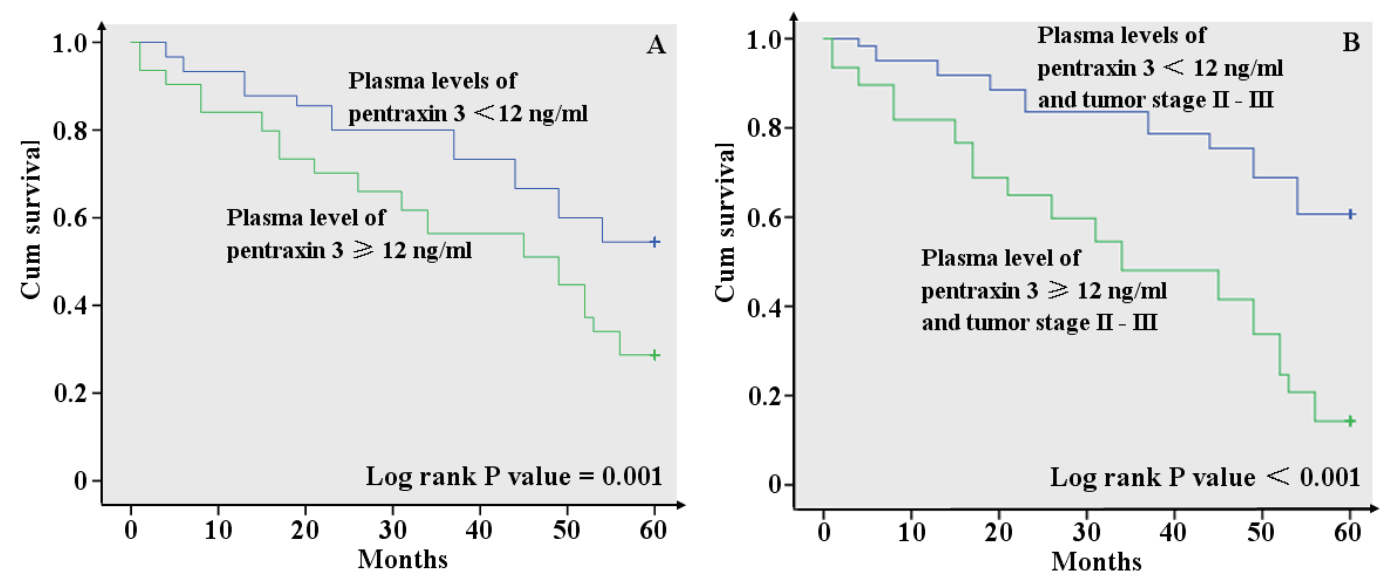

Fig. 3. Tumor free survival analyses of colorectal carcinoma patients according to tumor stage and plasma pentraxin 3 level. A: Tumor-free survival rate in 94 patients with plasma pentraxin 3 levels of $\geq 12 \mathrm{ng} / \mathrm{ml}$ was significantly lower than that in 90 patients with plasma pentraxin 3 levels of $<12 \mathrm{ng} / \mathrm{ml}(\log$ rank $P$ value $=0.001)$. B: In patients with tumor stage II or III, tumor-free survival rate in patients with plasma pentraxin 3 levels of $\geq 12 \mathrm{ng} / \mathrm{ml}$ was lower (Log rank P value $<0.001$ ). The data were obtained from 72 patients with plasma pentraxin 3 levels of $\geq 12 \mathrm{ng} / \mathrm{ml}$ and 66 patients with plasma pentraxin 3 levels of $<12 \mathrm{ng} / \mathrm{ml}$. 
Table 4. Associations of several potential prognostic factors and their combination with tumor relapse in the study.

\begin{tabular}{|c|c|c|}
\hline At admission & $\begin{array}{l}\text { Logistic univariate } \\
\text { regression analysis } \\
\text { OR }(95 \% \mathrm{CI})\end{array}$ & $\begin{array}{l}\text { Logistic multivariate } \\
\text { regression analysis } \\
\text { OR }(95 \% \mathrm{CI})\end{array}$ \\
\hline \multicolumn{3}{|l|}{ TNM stage $^{a}$} \\
\hline Stage I & Reference & Reference \\
\hline Stage II & $2.24(1.10 \sim 4.57)$ & $2.30(1.17 \sim 5.12)$ \\
\hline Stage III & $2.39(1.03 \sim 5.56)$ & $2.45(1.21 \sim 5.78)$ \\
\hline \multicolumn{3}{|l|}{ Pentraxin 3} \\
\hline$<12 \mathrm{ng} / \mathrm{ml}$ & Reference & Reference \\
\hline$\geqslant 12 \mathrm{ng} / \mathrm{ml}$ & $2.97(1.61 \sim 5.46)$ & $3.11(1.74 \sim 6.29)$ \\
\hline \multicolumn{3}{|l|}{ Combined analysis } \\
\hline$<12 \mathrm{ng} / \mathrm{ml}$ and stage I & Reference & Reference \\
\hline$\geqslant 12 \mathrm{ng} / \mathrm{ml}$ and stage I & $1.37(1.01 \sim 3.53)$ & $1.44(1.15 \sim 4.75)$ \\
\hline$<12 \mathrm{ng} / \mathrm{ml}$ and stage II-III & Reference & Reference \\
\hline$\geqslant 12 \mathrm{ng} / \mathrm{ml}$ and stage II-III & $9.25(4.08 \sim 20.99)$ & $9.77(4.81 \sim 21.13)$ \\
\hline \multicolumn{3}{|l|}{ Complement 3} \\
\hline$<1.6 \mathrm{~g} / \mathrm{L}$ & Reference & Reference \\
\hline$\geqslant 1.6 \mathrm{~g} / \mathrm{L}$ & $2.31(1.35 \sim 5.03)$ & $2.63(1.64 \sim 5.43)$ \\
\hline \multicolumn{3}{|l|}{ Complement 4} \\
\hline$<0.5 \mathrm{~g} / \mathrm{L}$ & Reference & Reference \\
\hline$\geqslant 0.5 \mathrm{~g} / \mathrm{L}$ & $3.97(1.72 \sim 5.66)$ & $4.08(1.45 \sim 5.41)$ \\
\hline \multicolumn{3}{|l|}{ Complement 5b9 } \\
\hline$<841.0 \mathrm{~g} / \mathrm{L}$ & Reference & Reference \\
\hline$\geqslant 841.0 \mathrm{~g} / \mathrm{L}$ & $2.77(1.15 \sim 6.32)$ & $2.89(1.31 \sim 6.83)$ \\
\hline
\end{tabular}

${ }^{a}$ Multivariate adjusted odds ratio were matched for sex, age, tumor site, tumor size, tumor differentiation and tumor stage. If $95 \%$ confidence interval did not include value one, it would be considered to be statistically significant.

TNM, tumor node metastasis; OR, odds ratio; 95\% CI, 95\% confidence interval.
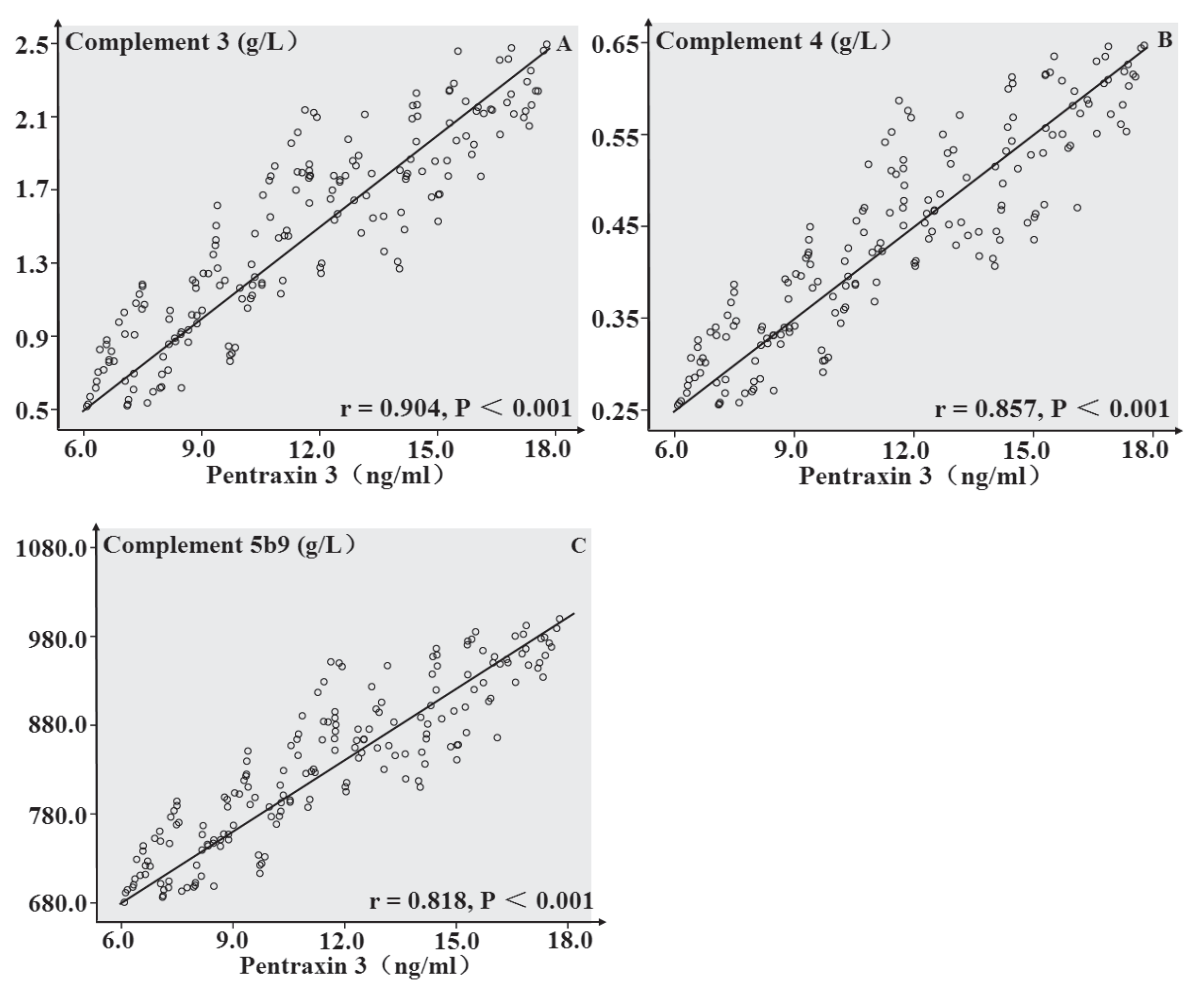

Fig. 4. Correlation analysis of plasma pentraxin 3 with complement 3, 4 and $5 \mathrm{~b} 9$ in colorectal carcinoma patients.

Plasma pentraxin 3 levels showed positive linear correlations with plasma levels of complement $3(\mathrm{r}=0.904, \mathrm{P}<0.001)$, complement $4(\mathrm{r}=0.857, \mathrm{P}<0.001)$ and complement $5 \mathrm{~b} 9(\mathrm{r}=0.818, \mathrm{P}<0.001)$. The data, shown in A-C, were obtained from 184 colorectal carcinoma patients. 
(see Fig. 2B-D), and high plasma levels of C3, C4 and C5b9 were associated with tumor relapse in CRC patients (OR: 2.63, 95\% CI: $1.64 \sim 5.43$, OR: 4.08, 95\% CI: $1.45 \sim$ 5.41 and OR: 2.89 , 95\% CI: $1.31 \sim 6.83$ ) (Table 4). In Fig. 4 , plasma levels of PTX3 had positive linear correlations with plasma levels of C3 ( $\mathrm{r}=0.904, \mathrm{P}<0.001), \mathrm{C} 4(\mathrm{r}=$ $0.857, \mathrm{P}<0.001)$ and $\mathrm{C} 5 \mathrm{~b} 9(\mathrm{r}=0.818, \mathrm{P}<0.001)$. We thus discovered higher degree of complement activation on admission in tumor relapse patients, and complement activation might play a potential role in prognostic significance of plasma PTX3 level.

\section{Discussion}

A previous study has reported that circulating inflammatory mediators including PTX3 are predictive of postoperative relapse after CRC surgery (Di Caro et al. 2016). In the present study, we also showed significantly higher plasma PTX3 levels in CRC patients compared with those in controls. Importantly, plasma levels of PTX3 decreased after resection and increased after relapse of CRC. Thus, we propose the important role of plasma PTX3 in the diagnosis and relapse monitoring of CRC.

During the follow-up period, 108 patients suffered from relapse of $\mathrm{CRC}$, and remaining 76 patients were tumor free following operation. Most demographic and pathologic factors were evenly distributed in relapse patients and tumor-free patients, except for plasma PTX3 levels on admission and tumor stage. In order to evaluate the association between plasma level of PTX3 and prognosis in patients, a logistic multivariate regression analysis was conducted. In such process, we had proved a 200\% increased relapse risk in patients with high plasma PTX3 levels compared with that in patients with low plasma PTX3 levels on admission. Furthermore, survival analysis also suggested a significant tumor-free survival advantage in patients with low plasma PTX3 levels on admission, which was consistent with the result obtained from logistic multivariate regression analysis. Therefore, plasma levels of PTX3 on admission might be an independent prognostic factor in CRC patients.

Prognostic significance of a single factor was limited, and multifactorial prognostic system might have a greater effect. We thus explored the relationship between prognosis and plasma PTX3 levels in patients with different tumor stages. After excluding patients with tumor stage I, logistic multivariate regression analysis and tumor-free survival analysis both revealed greater power of high plasma PTX3 levels on admission in poor prognosis prediction in CRC patients. Therefore, plasma level of PTX3 might have a greater prognostic power in advanced tumor stage patients, and a multifactorial prognostic system including plasma levels of PTX3 should be developed in the future.

A previous study suggested that plasma levels of PTX3 in patients with benign lung diseases were significantly higher than healthy subjects (Zhang et al. 2013). And, it was well known that patients with colorectal polyps or ulcerative colitis had a great risk to develop CRC. Therefore, we set up a colorectal polyp group in the present study, and found no difference in plasma level of PTX3 between colorectal polyp patients and healthy controls. However, we were unable to set up an ulcerative colitis group, because ulcerative colitis was a rare disease in China. Thus, it remains to be investigated whether ulcerative colitis affects the plasma PTX3 levels.

At present, underlying mechanisms of elevated plasma PTX3 levels in CRC were not fully elucidated. Some possible explanations for the association between PTX3 and CRC were listed as follows. (1) Chronic inflammation enhanced carcinogenesis partly through stimulating angiogenesis and inhibiting apoptosis (Jackson et al. 1997; Balkwill and Mantovani 2001). (2) Anti-inflammatory action might significantly reduce cancer risk including CRC (Akhmedkhanov et al. 2001; Moysich et al. 2002; Swede et al. 2005). (3) C-reactive protein (CRP) reflected inflammation level in the body, and elevated plasma levels of CRP in healthy subjects predicted long-term cancer risk (Allin et al. 2009). (4) PTX3 was another inflammatory factor, which had similar function with CRP, and a previous study revealed that plasma PTX3 levels increase more rapidly than CRP in pathological conditions (Okutani 2006).

Complements are useful innate defense system, which can participate in the elimination of microorganisms, apoptotic and damaged cells (Walport 2001), and pentraxins closely collaborates with complement system during such processes (Nauta et al. 2003). In other areas, complement system and PTX3 might also have a significant correlation. For example, a previous study had revealed a close association between PTX3 deposition and complement activation at the endothelial cell level in failed arteriovenous fistula (Castellano et al. 2010). Therefore, we explored the change of complement proteins in CRC patients in the study, and preliminarily discovered the activation of complement system in patients. We also demonstrated for the first time a linear correlation between PTX3 and complement proteins in CRC patients. However, more studies should be conducted in the future.

Taken together, plasma levels of PTX3 might have several potential clinical uses: First, plasma PTX3 levels might be an independent prognostic indicator, and might also be an important part of potential prognostic system in CRC patients; Second, plasma level of PTX3 might be an useful monitoring indicator for relapse in postoperative patients; Third, plasma level of PTX3 might partly reflect immune condition and complement activation in patients.

In conclusion, the present study has demonstrated that circulating PTX3 is predictive of the prognosis of CRC, and prognostic significance of PTX3 might enlarge in CRC patients with advanced tumor stage. We had also obtained some interesting, but not sufficient, evidence that prognostic significance of PTX3 might be partly involved the complement activation in CRC patients. 


\section{Conflict of Interest}

The authors declare no conflict of interest.

\section{References}

Akhmedkhanov, A., Toniolo, P., Zeleniuch-Jacquotte, A., Kato, I., Koenig, K.L. \& Shore, R.E. (2001) Aspirin and epithelial ovarian cancer. Prev. Med., 33, 682-687.

Allin, K.H., Bojesen, S.E. \& Nordestgaard, B.G. (2009) Baseline $\mathrm{C}$-reactive protein is associated with incident cancer and survival in patients with cancer. J. Clin. Oncol., 27, 22172224.

Balkwill, F. \& Mantovani, A. (2001) Inflammation and cancer: back to Virchow? Lancet, 357, 539-545.

Bottazzi, B., Bastone, A., Doni, A., Garlanda, C., Valentino, S., Deban, L., Maina, V., Cotena, A., Moalli, F., Vago, L., Salustri, A., Romani, L. \& Mantovani, A. (2006) The long pentraxin PTX3 as a link among innate immunity, inflammation, and female fertility. J. Leukoc. Biol., 79, 909-912.

Brenner, H., Kloor, M. \& Pox, C.P. (2014) Colorectal cancer. Lancet, 383, 1490-1502.

Castellano, G., Di Vittorio, A., Dalfino, G., Loverre, A., Marrone, D., Simone, S., Schena, F.P., Pertosa, G. \& Grandaliano, G. (2010) Pentraxin 3 and complement cascade activation in the failure of arteriovenous fistula. Atherosclerosis, 209, 241-247.

Cieślik, P. \& Hrycek, A. (2012) Long pentraxin 3 (PTX3) in the light of its structure, mechanism of action and clinical implications. Autoimmunity, 45, 119-128.

Compton, C.C. (2003) Colorectal carcinoma: diagnostic, prognostic, and molecular features. Mod. Pathol., 16, 376-388.

Di Caro, G., Carvello, M., Pesce, S., Erreni, M., Marchesi, F., Todoric, J., Sacchi, M., Montorsi, M., Allavena, P. \& Spinelli, A. (2016) Circulating inflammatory mediators as potential prognostic markers of human colorectal cancer. PLoS. One, 11, e0148186.

Ferlay, J., Shin, H.R., Bray, F., Forman, D., Mathers, C. \& Parkin, D.M. (2010) Estimates of worldwide burden of cancer in 2008: GLOBOCAN 2008. Int. J. Cancer, 127, 2893-2917.

Garlanda, C., Bottazzi, B., Bastone, A. \& Mantovani, A. (2005) Pentraxins at the crossroads between innate immunity, inflammation, matrix deposition, and female fertility. Annu. Rev. Immunol., 23, 337-366.

Germano, G., Frapolli, R., Simone, M., Tavecchio, M., Erba, E., Pesce, S., Pasqualini, F., Grosso, F., Sanfilippo, R., Casali, P.G., Gronchi, A., Virdis, E., Tarantino, E., Pilotti, S., Greco, A., et al. (2010) Antitumor and anti-inflammatory effects of trabectedin on human myxoid liposarcoma cells. Cancer Res., 70, 2235-2244

Guo, P., Huang, Z.L., Yu, P. \& Li, K. (2012) Trends in cancer mortality in China: an update. Ann. Oncol., 23, 2755-2762.

Infante, M., Allavena, P., Garlanda, C., Nebuloni, M., Morenghi, E., Rahal, D., Roncalli, M., Cavuto, S., Pesce, S., Monari, M., Valaperta, S., Montanelli, A., Solomon, D., Bottoni, E., Errico,
V., et al. (2016) Prognostic and diagnostic potential of local and circulating levels of pentraxin 3 in lung cancer patients. Int. J. Cancer, 138, 983-991.

Jackson, J.R., Seed, M.P., Kircher, C.H., Willoughby, D.A. \& Winkler, J.D. (1997) The codependence of angiogenesis and chronic inflammation. FASEB J., 11, 457-465.

Kondo, S., Ueno, H., Hosoi, H., Hashimoto, J., Morizane, C., Koizumi, F., Tamura, K. \& Okusaka, T. (2013) Clinical impact of pentraxin family expression on prognosis of pancreatic carcinoma. Br. J. Cancer, 109, 739-746.

Liu, C., Yao, Y. \& Wang, W. (2014) Pentraxin-3 as a prognostic marker in patients with small-cell lung cancer. Med. Oncol., 31, 207.

Locatelli, M., Ferrero, S., Martinelli, Boneschi, F., Boiocchi, L., Zavanone, M., Maria, Gaini, S., Bello, L., Valentino, S., Barbati, E., Nebuloni, M., Mantovani, A. \& Garlanda, C. (2013) The long pentraxin PTX3 as a correlate of cancerrelated inflammation and prognosis of malignancy in gliomas. J. Neuroimmunol., 260, 99-106.

Mantovani, A., Garlanda, C. \& Bottazzi, B. (2003) Pentraxin 3, a non-redundant soluble pattern recognition receptor involved in innate immunity. Vaccine, 21, 43-47.

Moysich, K.B., Menezes, R.J., Ronsani, A., Swede, H., Reid, M.E., Cummings, K.M., Falkner, K.L., Loewen, G.M. \& Bepler, G. (2002) Regular aspirin use and lung cancer risk. $B M C$ Cancer, $2,31$.

Nauta, A.J., Daha, M.R., van Kooten, C. \& Roos, A. (2003) Recognition and clearance of apoptotic cells: a role for complement and pentraxins. Trends Immunol., 24, 148-154.

Okutani, D. (2006) The role of long pentraxin 3, a new inflammatory mediator in inflammatory responses. Nihon Rinsho Meneki Gakkai Kaishi, 29, 107-113.

Savchenko, A., Imamura, M., Ohashi, R., Jiang, S., Kawasaki, T., Hasegawa, G., Emura, I., Iwanari, H., Sagara, M., Tanaka, T., Hamakubo, T., Kodama, T. \& Naito, M. (2008) Expression of pentraxin 3 (PTX3) in human atherosclerotic lesions. $J$. Pathol., 215, 48-55.

Swede, H., Mirand, A.L., Menezes, R.J. \& Moysich, K.B. (2005) Association of regular aspirin use and breast cancer risk. Oncology, 68, 40-47.

Takeda, N., Asai, K., Ijiri, N., Yamamoto, N., Watanabe, T., Kamoi, H., Kanazawa, H. \& Hirata, K. (2015) Pentraxin-3 as a biomarker for febrile neutropenia in patients with lung cancer. Osaka City Med. J., 61, 43-52.

Torre, L.A., Bray, F., Siegel, R.L., Ferlay, J., Lortet-Tieulent, J. \& Jemal, A. (2015) Global cancer statistics, 2012. CA Cancer J. Clin., 65, 87-108.

Walport, M.J. (2001) Complement. First of two parts. N. Engl. J. Med., 344, 1058-1066.

Zhang, D., Ren, W.H., Gao, Y., Wang, N.Y. \& Wu, W.J. (2013) Clinical significance and prognostic value of pentraxin-3 as serologic biomarker for lung cancer. Asian Pac. J. Cancer Prev., 14, 4215-4221. 